\title{
Cervical Transforaminal Injection: Review of the Literature, Complications, and a SUggested TeChNique
}

\author{
Robert E. Windsor, MD, Seneca Storm, MD, Ross Sugar, MD, and Diwakar Nagula, DO
}

Objective: The objective of this paper is to review the literature of cervical transforaminal injections, resulting complications, and to suggest a safe technique.

Methods: A systematic review of the literature was performed. Both the MEDLINE and EMBASE databases were searched for any article relating to cervical epidural injections, cervical transforaminal injections, and

The first known report of cervical epidural injections was by Dogliotti in 1933 (1). This followed the report of sacral epidural injection for low back pain by Cathelin (2) and Pasquier (3) in two separate reports in 1901 and Pages' report of lumbar epidural injection in 1921 (4). Epidural cortisone injections for the treatment of low back pain was first reported by Robechi (5) in 1952 and by Livre et al (6) in 1953 (6). The use of epidural injection for low back was first reported in the United States in 1960 by Brown (7) and Goebert et al (8). Since then, epidural cortisone injection have been widely used for the treatment of low back pain and lumbar radiculopathy (912). The use of cortisone in the epidural space for the treatment of radiculopathy, while somewhat intuitive at the time, has since been justified by a number of studies implicating inflammation as a root cause of neural irritation and damage (13-21). While there are few well-controlled studies regarding the use of lumbar epidural cortisone injections for the treatment of low back pain in the medical literature, the majority of those studies available are positive (22-24).

From Georgia Pain Physicians and Emory University, Atlanta, Georgia. Address Correspondence: Robert E. Windsor, MD, Georgia Pain Physicians, 2550 Windy Hill Rd., Suite 215, Marietta, Georgia- 30067. E-mail: rwindsor@aol.com

Funding: There was no external funding in preparation of this manuscript. complications relating to cervical epidural or cervical transforaminal injections. Finally, a method for performing a cervical transforaminal injection safely is described.

Conclusions: The review of the literature reavealed:

1. There is a paucity of literature regarding cervical transforaminal injections;

2. There is no accepted standard tech-

For decades many anesthesiologists felt the cervical interlaminar epidural procedure was too risky for routine use, due in part to the early problems encountered with epidural anesthesia in the neck and the narrow distance between the ligamentum flavum and the spinal cord $(25,26)$. At C7 this distance is only 1.5 to $2.0 \mathrm{~mm}$ versus 5.0 to $6.0 \mathrm{~mm}$ at $\mathrm{L} 2(25,27)$. The advent of fluoroscopy greatly aided the precision and safety of spinal injection techniques in the management of cervical radiculopathy and other painful conditions (28-35). Since the late 1980's, cervical epidural injections have been increasingly employed for neck pain, cervical radiculopathy, cervicogenic headaches, and complex regional pain syndrome unresponsive to sympathetic blockade (3655). Today, spinal injectionists are performing these injections routinely, however, even in the most trained hands, complications may occur (56-73).

As specialists pursue non-operative management of cervical radicular pain, cervical epidural injections have become common adjuncts to non-surgical management prior to resorting to surgery (11, $12,37,74,75)$. To date however, literature supporting cervical epidural injections remains sparse. The technique, outcome, and complications of cervical interlaminar epidurals are modestly documented in the literature. The use of fluoroscopically guided transforaminal epidural steroid injections (TFESI) has been report- nique for performing cervical transforaminal injections; and

3. More research and study must be performed regarding the risk versus benefit, technique, and outcome of cervical transforaminal injections.

Keywords: Neck pain, epidural, transforaminal epidural, epidural steroids, complications

ed for the treatment of cervical radicular pain but is by no means as well documented as its interlaminar counterpart $(37,77,78)$.

The TFESI technique has developed out of experience with its lumbar correlate. This technique is felt to be safer and more effective than its interlaminar counterpart. There is controversy over the safety issue as many physicians believe that the proximity of critical structures to the foramen makes the transforaminal injection technique inherently more dangerous $(79,80)$.

Despite the increasingly widespread use of this technique, detailed description of cervical transforaminal injections is notably absent from the current body of literature. As reports of serious neurological complications surface, concern over safety warrants further study and procedural guidelines. Currently, variation exists in nearly every aspect of these injections: type and volume of injectate, approach, and use of fluoroscopy and contrast. This review will present three cases of TFESIs associated with complications, review the available literature regarding TFESIs, and detail a technique that is compatible with the relevant neurovascular anatomy and has worked well in our experience.

\section{CAse Reports}

\section{Case \#1}

A 39-year old female with left leftsided neck and shoulder pain following 
a moving vehicle accident presented for treatment. A cervical magnetic resonance imaging (MRI) demonstrated a bulging C6-7 disc to the right without neural compression. The patient's treatment plan included an alternating right and left C7 TFESI on serial weeks. All procedures involved fluoroscopic guidance. The pain physician reported that a 25 G $31 \frac{1}{2}$-inch spinal needle was advanced to the posteroinferior quadrant of the foramen and contrast was injected to help confirm proper needle placement. The right C7 TFESI was performed without complication on week \#1 however on the week \#2, during the left C7 TFESI the patient had severe pain in the left upper extremity. The procedure was aborted and a left C6 TFESI was performed instead. Following the procedure the patient had a numb and weak left upper extremity. An MRI performed post-procedure demonstrated petechial hemorrhages in the lateral cord adjacent to the foramen. Neurological examination one week following the injection was consistent with a left $\mathrm{C} 7$ radiculopathy. The numbness and weakness in the left $\mathrm{C} 7$ distribution had not resolved over one year from the time of injection.

\section{Case \#2}

A 65-year old male with cervical spondylosis, chronic neck pain and left upper extremity pain presented for treatment. A left C6 TFESI was planned as part of the patient's treatment plan. The injection was performed under fluoroscopic guidance and the 25 G $31 / 2$-inch spinal needle was placed into the left C5-6 foramen. Anteroposterior and lateral views were checked prior to injecting contrast. The contrast was injected and revealed a left C6 spinal nerve outline. The physician planned to inject $2.5 \mathrm{~mL}$ of $0.75 \%$ bupivacaine and $6 \mathrm{mg}$ of Celestone. When $1.5 \mathrm{~mL}$ of this solution had been injected, the patient complained that he had a strange feeling in his head and said that he felt he was going to "pass out." Immediately following that statement, the patient had a generalized seizure, which lasted 34 minutes. Following the seizure activity, he had a prolonged postictal period lasting approximately 45 minutes. A brain computerized tomography (CT) scan, a brain MRI, and an electroencephalogram (EEG) performed within 24 hours of the injection were all normal. Follow-up MRI at 6-months and then at 12-months demonstrated mild atrophy of the hippocam- pus without other abnormalities. The patient has been unable to return to work due to a mild organic brain syndrome.

\section{Case \# 3}

A 39-year old male presented with neck pain and left-sided radicular symptoms. A cervical MRI demonstrated a left C5-6 disc bulge. A left C6 TFESI was planned. Using fluoroscopic guidance, a 22 G $3 \frac{1}{1} 2$-inch spinal needle into the left C5-6 foramen. A small amount of contrast was injected and revealed an "appropriate pattern." The physician intended to inject a $2.5 \mathrm{~mL}$ volume of fluid contained a $1: 1$ solution of $2 \%$ Lidocaine and Celestone Soluspan. Once 1.5 $\mathrm{mL}$ of this solution was injected, the patient stated that he was "light headed" and felt that he might pass out. The patient lost consciousness but had no seizure activity. The procedure was aborted and the patient's vital signs were supported. The patient regained consciousness within ten minutes, and it was noted that the both of his upper extremities were numb. He was unable to move his left upper extremity and the right upper extremity was paretic. Additionally, the patient was noted to be dysarthric with ataxia of both lower extremities. The right upper extremity paresis resolved within two hours of the injection. He did experience some recovery of the left upper extremity, although weakness and numbness in a C6 distribution persisted. Cervical MRI at the hospital demonstrated an acute posterior cord infarct from C1-C4 and a brain MRI demonstrated an acute cerebellar infarct.

\section{ReVIeW OF THE Literature}

\section{Cervical Interlaminar Injections and Cervical Epidural Anesthesia}

Fluoroscopy is now widely used and is recommended by many to allow for accurate needle placement (28-33). Stojanovic et al (31) found a 53\% false loss of resistance in cervical interlaminar epidural injections without fluoroscopic confirmation. However, the loss of resistance technique and hanging drop techniques without contrast confirmation are still widely used (79). Complications following cervical interlaminar injections and cervical epidural anesthesia have been reported. In their description of accidental spinal cord injury during epidural anesthesia, Bromage and Benumof (82) suggested the following guidelines: "1) As- sume that any report of lancinating pain during epidural puncture may be caused by mechanical stimulation of the spinal root or the cord itself and therefore is a clear signal to halt the advance of the epidural needle immediately; 2) perform the puncture below the termination point of the spinal cord, whenever practical and medically appropriate, though this is not practical for cervical or thoracic epidurals; and 3) when indications do exist for punctures above the termination of the spinal cord, the procedures should be performed with all due care by technically competent anesthesiologists and in an awake, responsive patient in all but rare circumstances (82).” In 1998, Hodges et al (61) reported two cases of spinal cord injury following interlaminar cervical epidural injection. The authors concluded that sedation should be used with caution during cervical injections (61). Others have suggested that sedation, in moderation, can be used safely and helps avoid untoward head movements (83). Regarding spinal cord embarrassment, a case of right leg monoplegia following introduction of a $25 \mathrm{G}$ needle and $0.3 \mathrm{~mL}$ of bupivacaine also has been reported during spinal anesthesia (84). This injury was confirmed by the discovery of hematomyelia at autopsy. Another case involving thoracic anesthesia and spinal cord injury proposed that introduction of the needle into the spinal cord should cause lancinating pain in an awake patient (85). However, one report of 120 percutaneous cervical cordotomies during which the cervical cord is punctured 2-4 times with a $22 \mathrm{G}$ needle electrode from an anterolateral approach at the C1-C2 level suggested that patients reported neither pain nor paresthesia during puncture, but did with electrical stimulation (86). This raises the possibility that needle introduction into the cord or neural structures alone, without injection or electrical perturbation, may not produce pain or injury. In fact, a case report and study of accidental injection of contrast medium into the cervical spine found that the mechanical effect of the volume of fluid rather than the contrast medium itself caused neurological symptoms (87). Despite the risks, Waldman (52) reported no serious complications in a series of 790 cervical interlaminar epidural cortisone injections.

\section{Cervical Transforaminal Injections}

In his report of cervical radiculopathy 
treated with TFESIs, Bush (37) demonstrated that 68 consecutive patients made satisfactory recovery without the need for surgery or major complication. Slipman et al $(77,88)$ reported that 12 out of 20 consecutive patients with cervical spondylotic radiculopathy treated with TFESIs experienced good or excellent results and were able to avoid surgery. Vallee et al (78) reported significant reduction in pain in 32 patients with cervical radiculopathy treated with TFESIs at 14 days and 6 months. The trials, while compelling, are without control groups, entailed no randomization, and are singlecentered as opposed to multi-centered. Such controlled trials provide evidence of successful outcomes in the management of lumbar radicular pain with transforaminal injections, however the equivalent level of study does not exist for TFESIs in the treatment of cervical radicular pain $(12,23,89)$.

TFESIs may seem to present a safer option for the treatment of cervical radiculopathy than the interlaminar approach and while few complications of this technique have been published, several cases of catastrophic injury are known to be sub-judice $(57,90)$. One case of fatal spinal cord infarction ascribed to a transforaminal injection of corticosteroids is published (62). A recent publication with the use of digital subtraction angiography demonstrated that careful technique alone may reduce, but does not eliminate the possibility of vascular injection. The authors of this paper suggest the use of live fluoroscopy and contrast medium (57). Additionally, Nash (90) suggested vasospasm of the medullary vessels from the introduction of needles into the foramen may occur potentially leading to a vascular spinal cord damage.

TFESI techniques have been described in the literature utilizing fluoroscopy and CT-guidance for confirmation of placement $(91,92)$.

Morvan et al (93) described an anterolateral approach similar to a cervical discographic approach. Vallee et al (78) described a technique in which the patient sits upright with their head held in position by a foam pad. Slipman et al (77) positioned the patient supine with a foam pad under the ipsilateral shoulder and the head rotated to the contralateral side to open the foramen to be injected up to the image intensifier of the fluoroscopy unit. A $22 \mathrm{G}$ spinal needle was placed into the target foramen under fluoroscopic guidance. The injection reportedly is carried out in this position. Bush and Hillier (37) also described an anterolateral approach in 68 patients with cervical radiculopathy. Larkin et al (94) described a technique in which a catheter is entered into the posterior epidural space via a more caudal

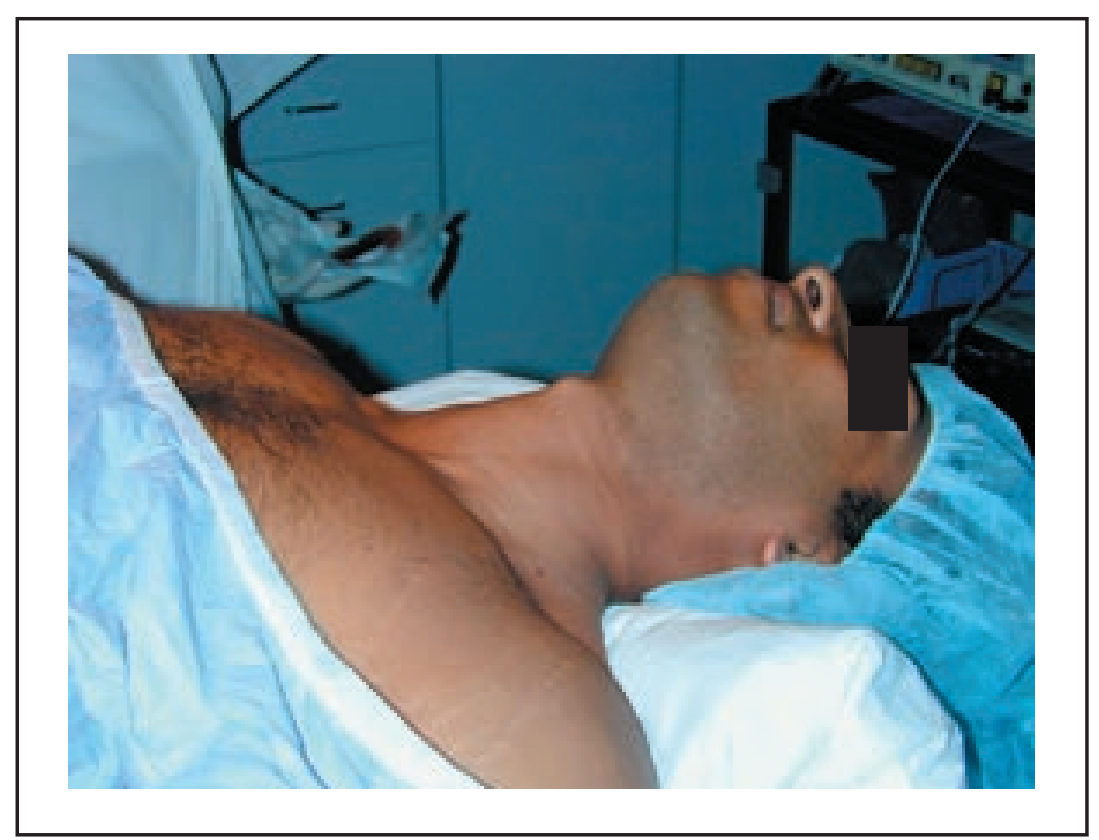

Fig 1. The patient is placed supine on the procedure table with tier neck in slight extension.

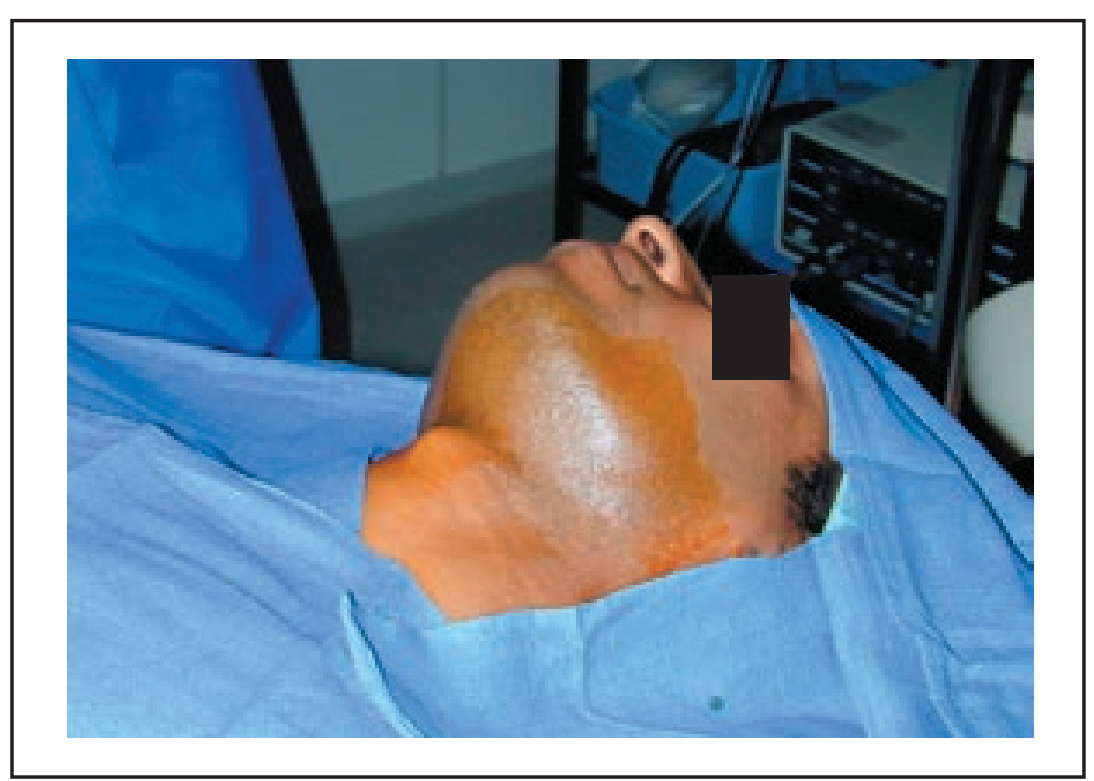

Fig 2. The patient is sterilely prepped with isopropyl alcohol, Chlorhexidine Gluconate and povidone-iodine from the angle of the mandible to below the clavicle and from the midline to the table. The region to be injected is then draped with sterile towels. Note that the patient's face remains uncovered. 
off all anti-platelet medications and is not anti-coagulated. Aspirin products should be stopped for a minimum of 7-10 days and anti-inflammatory agents should be stopped for a minimum of 72 hours prior to the injection $(95,96)$. If the patient is on Coumadin or other warfarin products, the patient must stop this medica-

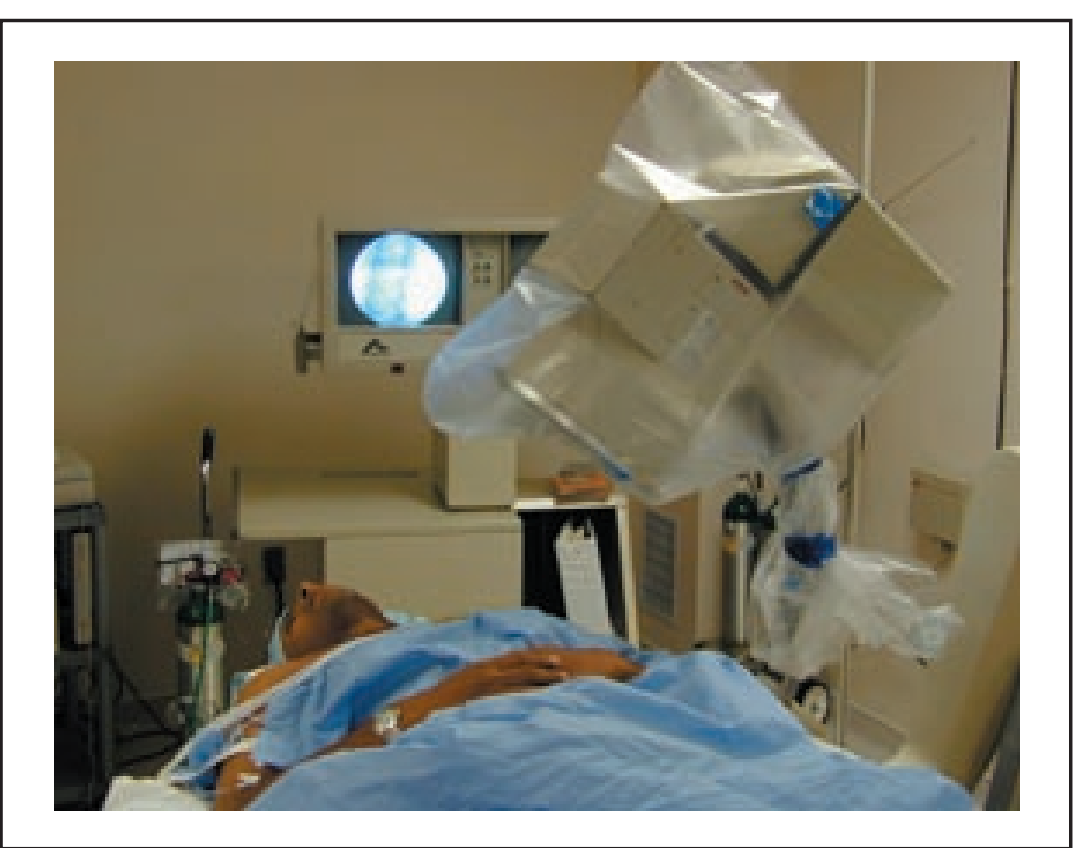

Fig 3. The C-arm is rotated approximately 45 degrees off the vertical and 10-20 degrees cephalad to caudal (anode to image intensifier). Note that the patient's neck has been rotated slightly to the opposite side to maximize surface area of the region of the neck to be injected.

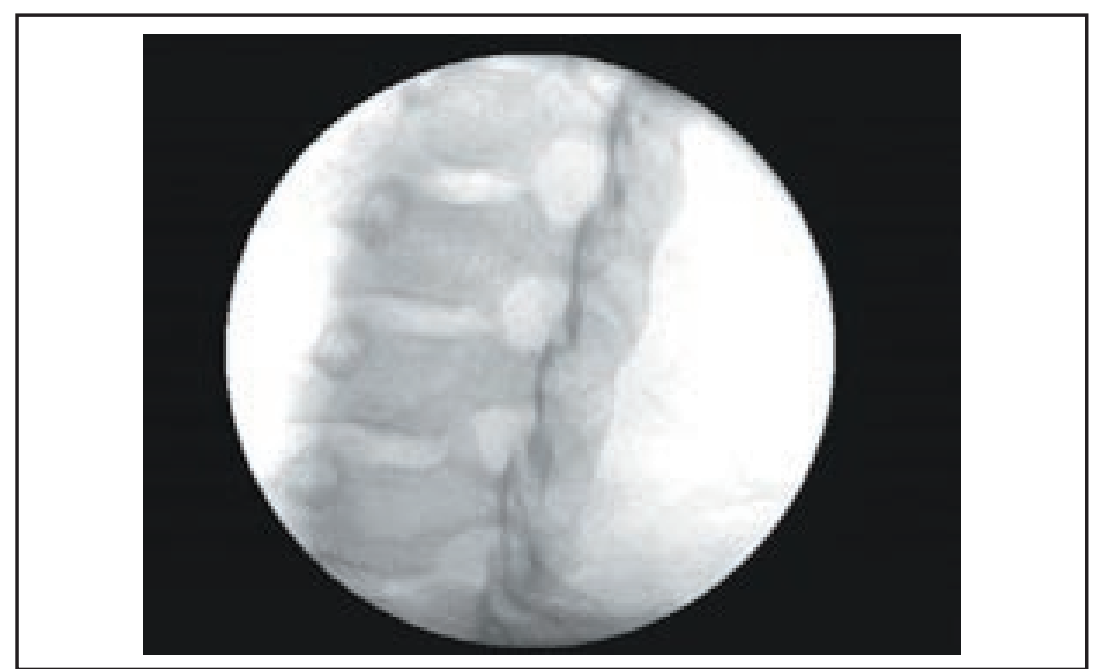

Fig 4. This is a digital image resulting from the fluoroscopic angle in Figure 3. Note that the fluoroscopic trajectory is parallel to the long axis of the foramina thus maximizing cross sectional dimensions of the image. the patient's internist prior to proceeding with the procedure.

The patient is positioned supine on the procedure table with the neck in slight extension; the shoulders depressed and the head rotated slightly away from the side to be injected to provide easier access. The skin is prepped in a sterile manner (Figs. 1-3), with isopropyl alcohol, chlorhexidine gluconate or povidone-iodine. The $\mathrm{C}$-arm is rotated into a 45-60 degree oblique position so that the largest cross-sectional area of the foramen to be injected is seen on the fluoroscopic monitor (Fig. 4). The skin and subcutaneous tissues are infiltrated with 2-4 $\mathrm{mL}$ of $1 \%$ Lidocaine in an en pointe manner. Care should be taken not to allow the anesthetizing needle to stray off course and potentially place other structures at risk for injection. A 25 G 31/2-inch spinal needle with a 30 -degree bend $8-10 \mathrm{~mm}$ from its distal tip is then advanced down to the lateral mass of the posterior foramen under live fluoroscopic visualization in the previously anesthetized tract of tissue. The needle tip should make contact with the lateral mass adjacent to the caudal half of the foramen (Figs. 5 and 6). Once bony contact has been made, either a depth gauge on the needle or the injectionist's fingers should be placed at the needle-skin interface to monitor the depth of the needle. With the needle depth monitored, the needle should be withdrawn $1 \mathrm{~mm}$ and then rotated under live fluoroscopic visualization so that the short arm (distal to the bend of the needle) of the needle is directed and advanced $1-2 \mathrm{~mm}$ anteriorly so that the needle tip is adjacent to the posteriorinferior foramen (Fig. 7). The needle is then rotated medially toward the extreme posterior portion of the foramen and advanced $2 \mathrm{~mm}$ beyond the point at which the depth gauge or injectionist's finger makes contact with the patient's skin (Fig. 8). At this point, the $\mathrm{C}$-arm should be rotated into the sagittal (AP) plane (Fig. 9). Care should be taken to make sure that the spinous processes of the segment being injected are equidistant from the pedicles on either side. Under live fluoroscopic visualization the needle should be slowly advanced until the needle is under the lateral border of the pedicle immediately above the target foramen. The needle tip should not be beyond the mid 


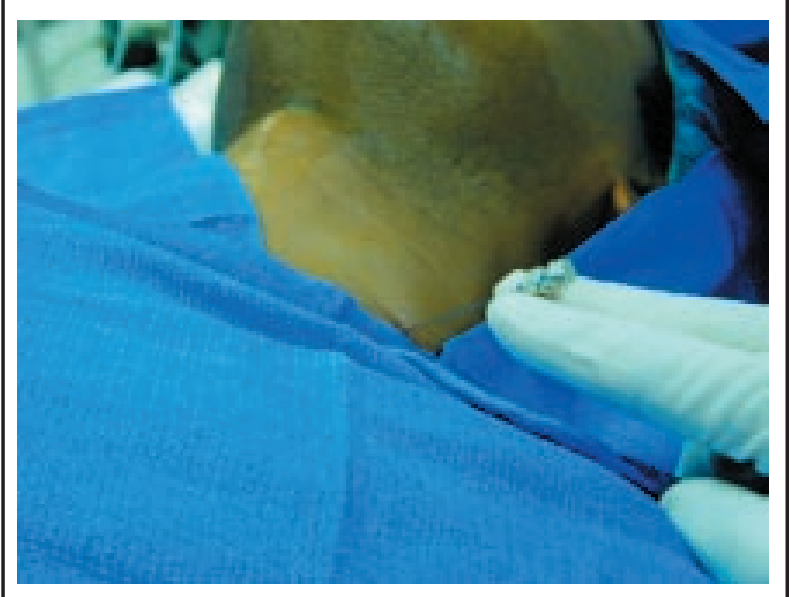

Fig 5. A 25 G 3 1/2 inch spinal needle with a 30-degree bend from the distal tip has been advanced down to the left C6 inferior articular process in preparation for entering the left C5-6 foramen. The inferior articular process provides an excellent bony landmark for a stepwise entrance into the cervical foramen.

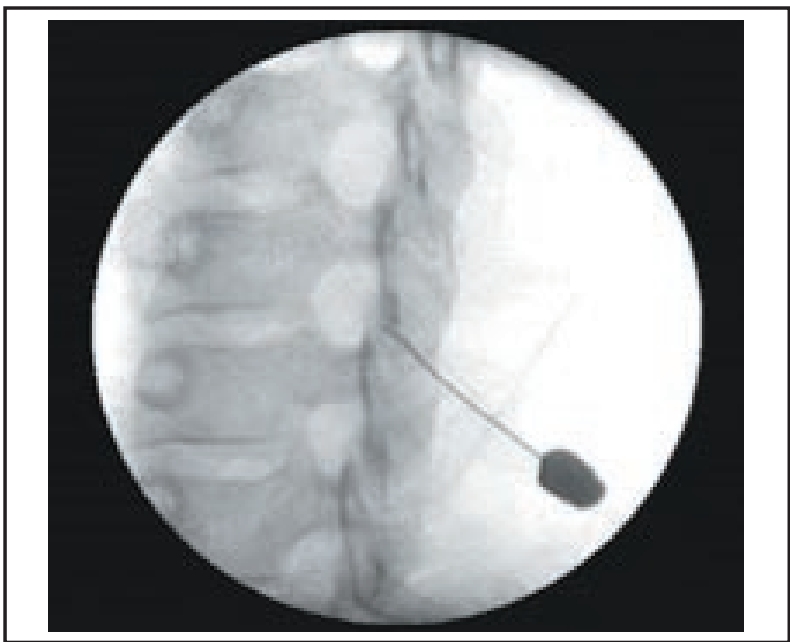

Fig 7. The $3 \frac{1}{2}$ inch spinal needle has been rotated and advanced anteriorly 1-2 mm so that the tip of the needle rests at the posterior inferior portion of the left C5-6 foramen.

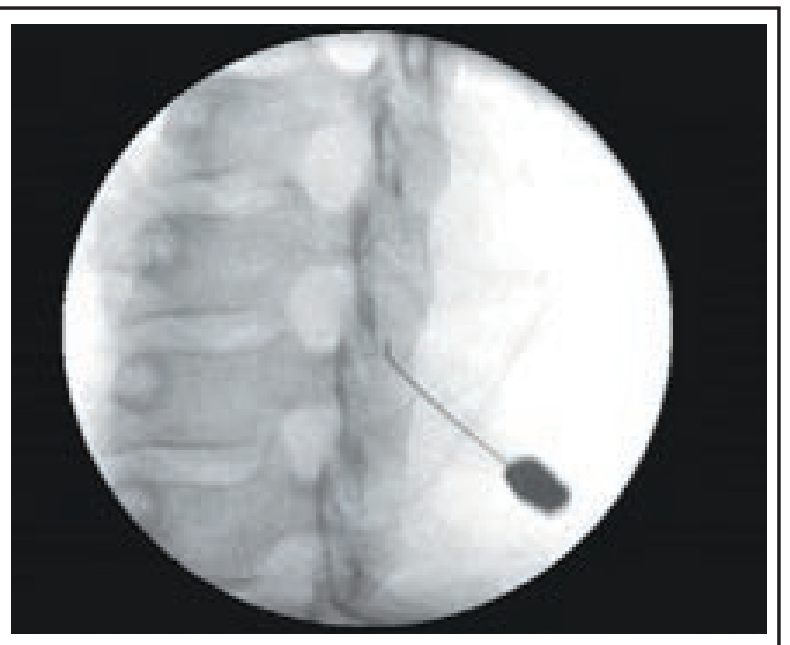

Fig 6. This fluoroscopic image demonstrates the $25 \mathrm{G}$ $31 / 2$ inch spinal needle in Figure 5 down to the left C6 inferior articular process. portion of the pedicle in a true AP view. From this step on until the procedure is finished, injections through the needle should be performed under live fluoroscopic visualization to confirm that the needle is not being inadvertently advanced medially into the spinal canal. A small amount of non-ionic contrast agent $(0.5-1.0 \mathrm{~mL})$ should be injected to determine needle placement (Fig. 10). Ideally, contrast should be injected under live digital subtraction fluoroscopy in order to better identify subtle intra-arterial injections that may otherwise be missed on plain fluoroscopy (Fig. 11). The contrast material should outline the spinal nerve, enter the spinal canal and begin to course along the medial border of the pedicle above or below unless there is an obstruction to fluid flow such as disc herniation or spondylotic spur. It should not be rapid- ly carried away in a cephalad direction suggesting a vertebral or radicular artery injection or in a serpentine manner suggesting a Batson's plexus injection. The contrast agent should also not rapidly diffuse across the midline in a homogeneous manner suggesting a subarachnoid injection and the patient should experience essentially no pain with either needle placement or injection. Extreme pain or lancinating pain 


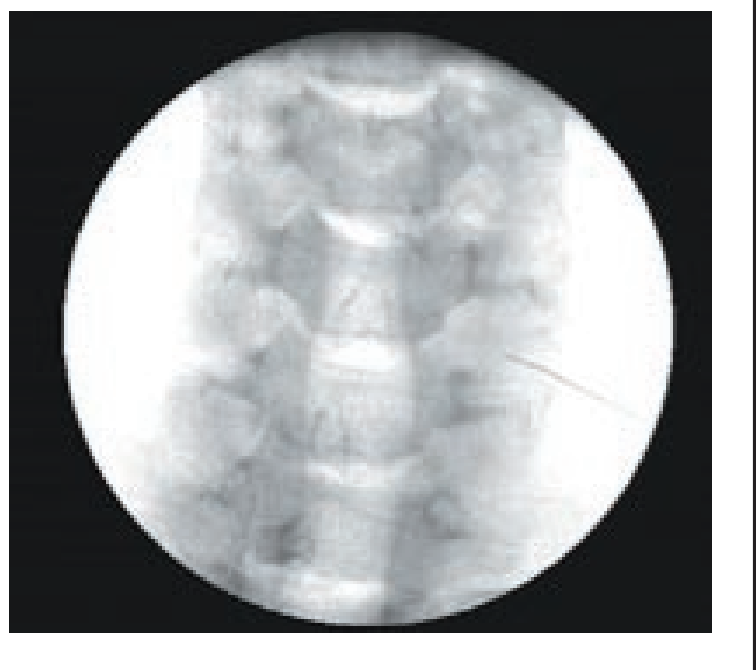

Fig. 9 An A-P image of the cervical spine demonstrating the tip of the spinal needle in the inferior portion of the left C5-6 foramen and immediately under the lateral half of the left C5 pedicle. Note that the spinous processes bisect the horizontal inter-pedicular line demonstrating an exact AP view.

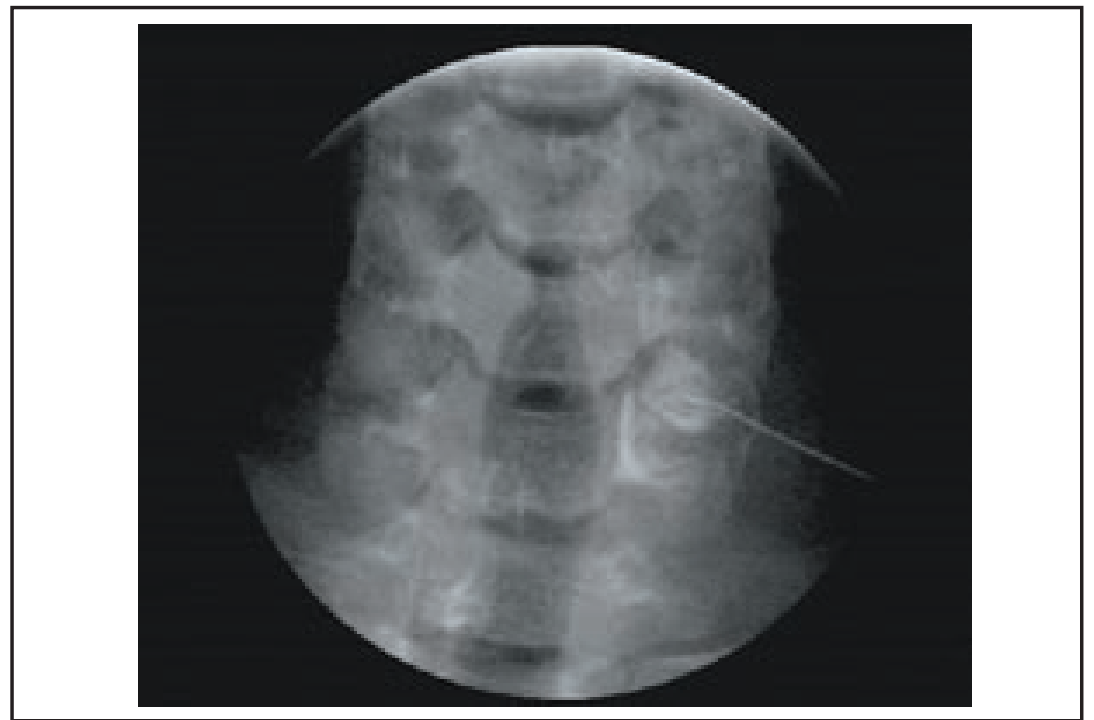

Fig 11. Live digital subtraction fluoroscopy taken during active injection failed to demonstrate vascular uptake.

either upon needle placement or injection suggests an intraneural positioning of the needle. A spot film should be taken of the resulting contrast outline for documentation purposes. Once the needle has been properly placed, 0.5 $\mathrm{mL}$ of $1 \%$ Lidocaine should be injected as a test dose under live fluoroscopic vi-

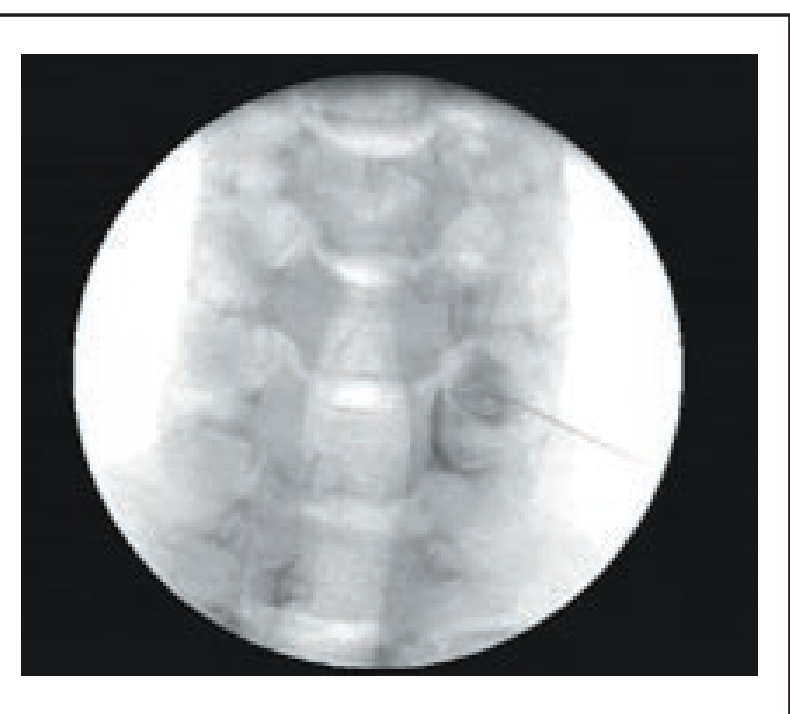

Fig 10. This image demonstrates contrast medial to the left C6 pedicle.

symptoms, the injectionist should inject the intended medication slowly under live fluoroscopic visualization for the same reason as stated above.

A typical selective epidural cortisone injection should consist of $1 \mathrm{~mL}$ of $2 \% \mathrm{Li}-$ docaine and $1 \mathrm{~mL}$ of Celestone Soluspan $(6 \mathrm{mg})$ or the equivalent. Other similar "cocktails" are acceptable such as $1 \mathrm{~mL}$ of $0.5 \%$ Bupivacaine, $1 \mathrm{~mL}$ of Celestone Soluspan, and $1 \mathrm{~mL}$ of $1 \%$ Lidocaine. The reason for injecting a local anesthetic is to provide immediate analgesia and to theoretically augment the "wind down".

\section{CONCLUSION}

Cervical transforaminal epidural injections are currently clinically important in the management of cervical radicular pain. While preliminary reports of clinical outcomes are encouraging, only a paucity of literature regarding these injections exists. To date there is no accepted standard technique for performing transforaminal epidural steroid injections. Physicians performing these procedures must make themselves aware of the serious complications that are now being recognized and reported. Establishing an appropriate mechanism for reporting, evaluating and studying these techniques and outcomes is warranted with the aim of ensuring patient safety. More research and study must be performed regarding the risk versus benefit, technique, and outcome of transforaminal epidural steroid injections. 


\section{Author Affiliation:}

Robert E. Windsor, MD

Program Director \& President

Georgia Pain Physicians

Emory University

2550 Windy Hill Road, Suite 215

Atlanta, GA 30067

E-mail: rwindsor@aol.com

\section{Seneca Storm, MD}

Fellow

Georgia Pain Physicians

Emory University

2550 Windy Hill Road, Suite 215

Atlanta, GA 30067

E-mail: senecastorm@hotmail.com

\section{Ross Sugar, MD}

Faculty

Georgia Pain Physicians

Emory University

2550 Windy Hill Road, Suite 215

Atlanta, GA 30067

\section{Diwakar Nagula, DO}

Fellow

Georgia Pain Physicians

Emory University

2550 Windy Hill Road, Suite 215

Atlanta, GA 30067

\section{REFERENCES}

1. Dogliotti A. Segmental peridural anesthesia. Am J Surg 1933; 20:107.

2. Cathelin F. Mode d'action de a cocaine injete daus l'escapte epidural par le procede du canal sacre. Comptes Rendies des Senaces de la Societe de Biologic et de ses Filliales, 1901; 53:452-453.

3. Pasquier NM, Leri D. Injection intra-et extradurales de cocaine a dose minime daus le traitment de la sciatique. Bull Gen Ther 1901; 142:196.

4. Pages E. Anestesia Metamerica. Rev Sanid Mil Madr 1921; 11:351-385.

5. Robechi A, Capra R. L'idrocortisone (composto $\mathrm{F}$ ). Prime esperienze cliniche in campo reumatolgico. Minerva Med 1952; 98: 1259-1263.

6. Lievre J, Block-Michel H, Attali P. L'injection transsacree wtude clinique et radioogique. Bull Soc Med 1957; 73:11101118.

7. Brown J. Pressure anesthesia and back manipulation. North Med 1960; 59:905909.

8. Goebert HW, Jallo SJ, Gardner WJ et al. Painful radiculopathy treated with epidural injections of procaine and hydrocortisone acetate: Results in 113 patients. Anesth Analg 1961; 140:130-134.

9. Mulligan K, Rowlingson J. Epidural steroids. Curr Pain Headache Rep 2001; 5: 495-502.
10. Waldman S. Epidural nerve block. In Weiner RS (ed). Innovations in Pain Management. PMD Press, Orlando, 1990, pp 45 .

11. Pawl R, Matz M, Wissinger J et al. Epidural steroids for cervical and lumbar radiculopathy. Surg Neurol 1996; 46:455457.

12. Riew DK, Yin $Y$, Gilula $L$ et al. The effect of nerve-root injections on the need for operative treatment of lumbar radicular pain: $\mathrm{A}$ prospective, randomized, controlled, double blind study. J Bone Joint Surg Am 2000; 82:1589-1593.

13. Saal J, Franson R, Dobrow R. High levels of inflammatory phospholipase A2 activity in lumbar disc herniations. Spine 1990; 15: 674-678.

14. Franson R, Saal J, Saal J. Human disc phospholipase A2 is inflammatory. Spine 1992; 17:S129-S132.

15. Saal J. The role of inflammation in lumbar pain. Spine 1995; 20:1821-1827.

16. Lee $\mathrm{H}$, Weinstein J, Meller $\mathrm{S}$ et al. The role of steroids and their effects on phospholipase A2: An animal model of radiculopathy. Spine 1988; 23:1191-1196.

17. Hayashi N, Weinstein JN, Meller ST et al. The effect of epidural injection of betamethasone or bupivacaine in a rat model of lumbar radiculopathy. Spine 1998; 23: 877-885.

18. Marshall L, Trethewie E, Curtain C. Chemical radiculitis: A clinical, physiological, and immunological study. Clin Orthop 1977; 190:61-67.

19. Doita M, Kanatani T, Harada T et al. Immunohistologic study of the ruptured intervertebral disc of the lumbar spine. Spine 1996; 21:235-241.

20. Haro H, Shinomya K, Komori $\mathrm{H}$ et al. Upregulated expression of the chemokines in herniated nucleus pulposus resorption. Spine 1996; 21:1647-1652.

21. McCarron R, Wimpee M, Hudkins $P$ et al. The inflammatory effect of nucleus pulposus. A possible element in the pathogenesis of low back pain. Spine $1987 ; 12: 760-$ 764 .

22. Weinstein S, Herring S. Epidural steroid injections. NASS Contemp Concepts 1994; Oct:1-11.

23. Vad VD, Bhat AL, Lutz GE et al. Transforaminal epidural steroid injections in lumbosacral radiculopathy: a prospective randomized study. Spine 2002; 27:11-16.

24. Karpinnen J, Malmivaara A, Kurunlahti M et al. Periradicular infiltration for sciatic. A randomized controlled trial. Spine 2001; 26:1059-1067.

25. Bromage P. Anatomy. In Bromage P (ed). Epidural anesthesia. WB Saunders, Philadelphia, 1978, pp 8-20.

26. Raj P. Central neural blocks. In Raj P, Nolte H, Stanton-Hicks M (eds). Illustrated Manual of Regional Anesthesia. Springer-Verlag, Heidelberg, 1988.

27. Han K, Kim C, Park S et al. Distance to the adult cervical epidural space. Reg Anesth Pain Med 2003; 28:95-97.

28. Renfrew D, Moore T, Kathol M. Correct placement of epidural steroid injections: fluoroscopic guidance and contrast administration. Am J Neuroradiol 1991; 12: 1003-1007.

29. el-Khoury G, Ehara S, Weinstein J. Epidural steroid injection: a procedure ideally performed with fluoroscopic control. Radiology 1988; 168:554-557.

30. Stitz M, Sommer H. Accuracy of blind versus fluoroscopically guided caudal epidural injection. Spine 1999; 24:1371-1376.

31. Stojanovic M, Vu T, Caneris O. The role of fluoroscopy in cervical epidural steroid injections: an analysis of contrast dispersal patterns. Spine 2002; 27:509-514.

32. White A, Derby R, Wynne G. Epidural injections for the diagnosis and treatment of low-back pain. Spine 1980; 5:78-86.

33. White $A$. Injection techniques for the diagnosis and treatment of low back pain. Orthop Clin North Am 1983; 14:553-567.

34. Mehta M, Salmon N. Extradural block. Confirmation of the injection site by X-ray monitoring. Anaesthesia 1985; 40:10091012.

35. Silbergleit R, Mehta B, Sanders W. Imaging-guided injection techniques with fluoroscopy and CT for spinal pain management. Radiographics 2001; 21:927-939.

36. Mori K, Yamashita J, Yamasaki S et al. Management of cervical syndromes with epidural injection of steroid hormones. Geka Chiryo 1969; 21:397-404.

37. Bush K, Hillier S. Outcome of cervical radiculopathy treated with periradicular/ epidural corticosteroid injections: A prospective study with independent clinical review. Eur Spine J 1996; 5:319-325.

38. Shulman J. Treatment of neck pain with cervical epidural steroid injection. Reg Anesth 1986; 11:92-94.

39. Fanciullo G, Hanscom B, Seville J. An observational study of the frequency and pattern of use of epidural steroid injection in 25,479 patients with spinal and radicular pain. Reg Anesth Pain Med 2001; 26:511.

40. Weinstein S, Herring S, Derby R. Contemporary concepts in spine care: Epidural steroid injections. Spine 1995; 20:18421846.

41. Shulman M, Nimmagadda U, Valenta A. Cervical epidural steroid injection for pain of cervical spine origin. Anesthesiology 1984; 61:A233.

42. Rowlingson J, Kirschenbaum L. Epidural analgesic techniques in the management of cervical pain. Anesth Analg 1986; 65: 938-942.

43. Martelletti P, Di Sabato F, Granata M. Epidural corticosteroid blockade in cervicogenic headache. Eur Rev Med Pharmacol Sci 1998; 2:31-36.

44. Martelletti P, Di Sabato F, Granata M. Failure of long-term results of epidural steroid 
injection in cervicogenic headache. Eur Rev Med Pharmacol Sci 1998; 2:10.

45. Martelletti P, Di Sabato F, Granata M. Epidural steroid-based technique for cervicogenic headache diagnosis. Funct Neurol 1998; 13:84-87.

46. Castagnera L, Maurette P, Pointillart $V$ et al. Long-term results of cervical epidural steroid injection with and without morphine in chronic cervical radicular pain. Pain 1994; 58:239-243.

47. Stav A, Ovadia L, Sternberg A et al. Cervical epidural steroid injection for cervicobrachialgia. Acta Anaesthesiol Scand 1993; 37:562-566.

48. Ferrante F, Wilson S, Evans P et al. Clinical classification as a predictor of therapeutic outcome after cervical epidural steroid injection. Spine 1993; 18:730-736.

49. Cicala R, Jones J, Westbrook L. Causalgic pain responding to epidural but not to sympathetic nerve blockade. Anesth Analg 1990; 70:218-219.

50. Cicala R, Thoni K, Angel J. Long-term results of cervical epidural steroid injections. Clin J Pain 1989; 5:143-145.

51. Cronen M, Waldman S. Cervical steroid epidural nerve blocks in the palliation of pain secondary to intractable tensiontype headaches. J Pain Symptom Manage 1990; 5:379-381.

52. Waldman S. Complications of cervical epidural nerve blocks with steroids: a prospective study of 790 consecutive blocks. Reg Anesth 1989; 14:149-151.

53. Dirksen R, Rutgers M, Coolen J. Cervical epidural steroids in reflex sympathetic dystrophy. Anesthesiology 1987; 66:7173.

54. Botwin K, Castellanos R, Rao S. Complications of fluoroscopically guided interlaminar cervical epidural injections. Arch Phys Med Rehabil 2003; 84:627-633.

55. Catchlove R, Braha R. The use of cervical epidural nerve blocks in the management of chronic head and neck pain. Can Anaesth Soc J 1984; 31:188-191.

56. Simopoulos T, Peeters-Asdourian C. Pneumocephalus after cervical epidural steroid injection. Anesth Analg 2001; 92:15761577.

57. Baker R, Dreyfuss P, Mercer S et al. Cervical transforaminal injection of corticosteroids into a radicular artery: a possible mechanism for spinal cord injury. Pain 2003; 103:211-215.

58. Field J, Rathmell J, Stephenson J. Neuropathic pain following cervical epidural steroid injection. Anesthesiology 2000; 93: 885-888.

59. Reitman C, Watters W. Subdural hematoma after cervical epidural steroid injection. Spine 2002; 27: E174-E176.

6o. Stoll A, Sanchez M. Epidural hematoma after epidural block: Implications for its use in pain management. Surg Neurol 2002; 57:235-240.

61. Hodges S, Castleberg R, Miller T et al. Cer- vical epidural steroid injection with intrinsic spinal cord damage. Two case reports. Spine 1998; 23:2137-2142.

62. Brouwers P, Kottnik E, Simon $M$ et al. A cervical anterior artery syndrome after diagnostic blockade of the right C6 nerve root. Pain 2001; 91:397-399.

63. Manchikanti L. Cervical epidural steroid injection with intrinsic spinal cord damage. Spine 1999; 24:1170-1172.

64. Siegfried R. Development of complex regional pain syndrome after a cervical epidural steroid injection. Anesthesiology 1997; 86:1394-1396.

65. Williams K, Jackowski A, Evans P et al. Epidural hematoma requiring surgical decompression following repeated cervical epidural steroid injections for chronic pain. Pain 1990; 42:197-199.

66. Cicala R, Westbrook L, Angel J. Side effects and complications of cervical epidural steroid injections. J Pain Symptom Manage 1989; 4:64-66.

67. Waldman S. Cervical epidural abscess after cervical epidural nerve block with steroids. Anesth Analg 1991; 72:717-718.

68. Abram S, O'Connor T. Complications associated with epidural steroid injections. Reg Anesth 1996; 21:149-162.

69. Houten J, Errico T. Paraplegia after lumbosacral nerve root block: Report of three cases. Spine J 2002; 2:70-75.

70. Dickman C, Shedd S, Spetzler R et al. Spinal epidural hematoma associated with epidural anesthesia: Complications of systemic heparinization in patients receiving peripheral vascular thrombolytic therapy. Anesthesiology 1990; 72:947-950.

71. Kirkpatrick D, Goodman S. Combined subarachnoid and subdural spinal hematoma following spinal puncture. Surg Neurol 1975; 3:109-111.

72. Onishchuk J, Carlsson C. Epidural hematoma associated with epidural anesthesia: complications of anticoagulant therapy. Anesthesiology 1992; 77:1221-1223.

73. Wilkes N, Mallett S, Peachey T. Vertebral canal hematoma is a hazard of spinal-epidural anaesthesia in patients treated with low-molecular weight heparins. $\mathrm{Br} / \mathrm{An}$ aesth 1999; 83:352-353.

74. Pawl RP, Anderson W, Shulman M. Effect of epidural steroids in the cervical and lumbar region on surgical intervention for diskogenic spondylosis. In Fields HL, Dubner R, Cerveero F (eds). Advances in Pain Research and Therapy. Raven Press, New York, 1985, pp 791-798.

75. Sampath P, Bendebba M, Davis J et al. Outcome in patients with cervical radiculopathy: prospective, multicenter study with independent clinical review. Spine 1999; 24:591-597.

76. Persson L, Carlsson C, Carlsson A. Longlasting cervical radicular pain managed with surgery, physiotherapy, or a cervical collar. Spine 1997; 22:751-758.

77. Slipman C, Lipetz J, Jackson $\mathrm{H}$ et al. Ther- apeutic selective nerve root block in the nonsurgical treatment of atraumatic cervical spondylotic radicular pain: A retrospective analysis with independent clinical review. Arch Phys Med Rehabil 2000; 81:741-746.

78. Vallee J, Feydy A, Carlier R et al. Chronic cervical radiculopathy: Lateral-approach periradicular corticosteroid injection. $\mathrm{Ra}$ diology 2001; 218:886-892.

79. Slosar P Jr, White A, Wetzel F. Controversy. The use of selective nerve root blocks: $\mathrm{Di}$ agnostic, therapeutic, or placebo? Spine 1998; 15:2253-2256.

8o. Furman M, Giovanniello M, O’Brien E. Incidence of intravascular penetration in transforaminal cervical epidural steroid injections. Spine 2003; 28:21-25.

81. Cluff R, Mehio A, Cohen S et al. The technical aspects of epidural steroid injections: A national survey. Anesth Analg 2002; 95: 403-408.

82. Bromage PR, Benumof JF. Reg Anesth 1998; 23:104-107.

83. Derby R. Discussion of cervical epidural steroid injection with intrinsic spinal cord damage. Two case reports. Spine 1998; 23:2141-2142.

84. Greaves J. Serious spinal cord injury due to hematomyelia in a patient treated with low-dose heparin. Anesthesia 1997; 52: 150-154.

85. Mayall M, Calder I. Spinal cord injury following an attempted thoracic epidural. Anesthesia 1999; 54:990-994.

86. Pounder D, Elliot S. An awake patient may not detect spinal cord puncture. (Correspondence) Anesthesia 2000; 55:194.

87. Servo A, Laasonen E. Accidental introduction of contrast medium into the cervical spinal cord. A case report. Neuroradiology $1985 ; 27: 80-82$.

88. Slipman C, Chow D. Therapeutic spinal corticosteroid injections for the management of radiculopathies. Phys Med Rehabil Clin N Am 2002; 13:691-711.

89. Lutz G, Vad V, Wisneski R. Fluoroscopic transforaminal lumbar epidural steroids: An outcome study. Arch Phys Med Rehab 1998; 79:1362-1366.

90. Nash T. Comment on A cervical anterior spinal artery syndrome after a diagnostic blockade of the right $\mathrm{C} 6$ nerve root. PJAM Brouwers et al. Pain 91 (2001) 397-399, Pain 2002, 92:217-218.

91. Berger O, Dousset V, Delmer O et al. Evaluation of the efficacy of foraminal infusions of corticosteroids guided by computed tomography in the treatment of radicular pain by foraminal injection. J Radiol 1999; 80:917-925.

92. Zennaro H, Dousset V, Viaud B et al. Periganglionic foraminal steroid injections performed under CT control. AJNR Am J Neuroradiol 1998; 19:349-352.

93. Morvan G, Mompoint D, Bard M et al. Direct intra-foraminal injection of corticosteroids in the treatment of cervico-brachial 
pain. In Bard M, Laredo J (eds). Interventional Radiology in Bone and Joint. Spring. er-Verlag, New York, 1988, pp 253-257.

94. Larkin T, Carragee E, Cohen S. A novel technique for delivery of epidural steroids and diagnosing the level of nerve root pathology. J Spinal Disord Tech 2003; 16:186-192.
95. Horlocker T, Wedel D, Benzon $\mathrm{H}$ et al. Regional anesthesia in the anticoagulated patient: Defining the risks (the second ASRA Consensus Conference on Neuraxial Anesthesia and Anticoagulation). Reg Anesth Pain Med 2003; 28:172-197.

96. Windsor R, Pinzon E, Gore H. Complica- tions of common selective spinal injections: prevention and management. $\mathrm{Am}$ J Orthop 2000; 29:759-770.

97. Wysowski D, Talarico L, Bacsanyi J et al. Spinal and epidural hematoma and lowmolecular-weight heparin. N Engl J Med 1998; 338:1774-1775. 
